\title{
Understanding the Spread of Malignant Conflict: A Dynamical Systems Perspective
}

\author{
Naira Musallam, Peter T. Coleman, and Andrzej Nowak
}

"The other day I was taking a walk across the shore of Jaffa [a Palestinian town prior to 1948] and I was looking at the houses that now have been converted into these galleries [...] They are very nice houses with traditional Arabic Architecture, but I got so upset just looking at them. For someone who did not grow up in the conflict, they are just houses. For me, it is not just a house, it is a house that used to belong to my relatives who, by the way, today live in a refugee camp in the Gaza Strip. I look at the house and it brings up all the history, the injustice, and the emotions. By that time, I can't even stand seeing the face of any Israeli passing by me. It doesn't matter who" (anonymous Palestinian, 2007).

The pernicious effects of a conflict should not be judged solely by its intensity, its duration, or even its consequences. These criteria are not to be dismissed as unimportant, of course, but in focusing on them scholars and practitioners may be overlooking a feature of conflict that may prove to be more predictive of the long-term social landscape in which the conflict is embedded. As the above quote illustrates, the enmity associated with some social conflicts can spread and permeate previously unaffected aspects of community life; transforming them into triggers or symbols of resentment and hate. We see this occur when a walk at the shore and the sight of beautiful homes fuels a latent sense of outrage and once again turns person against person, group against group.

The current paper aims to enhance our understanding of how negativity in conflict spreads, and to suggest some preliminary methods for measuring how this form of contagion occurs in conflicts overtime. Accordingly, the paper employs basic principles from dynamical systems theory (see Vallacher and Nowak, 2007), a theoretical perspective that informs how complex systems evolve and develop over time. These 
principles can move the field forward in terms of the conceptualization and measurement of the spread of negativity in conflict over time.

The paper includes the following sections: 1 ) a discussion of the characteristics of malignant social conflicts, 2) a review of the literature on psychological, social, and structural dimensions related to conflict pervasiveness, 3) findings from an exploratory study conducted with Israelis and Palestinians on the spread of destructive conflict, and 4) a discussion of the relevance of dynamical-systems theory for conceptualizing and measuring the spread of negativity in conflict.

\section{Malignant Social Conflicts}

Deutsch (1983, 1985) described malignant social conflicts as "a stage (of escalation) which is increasingly dangerous and costly and from which the participants see no way of extricating themselves without becoming vulnerable to an unacceptable loss in a value central to their self-identities or self-esteem" (1985, p. 263). These processes can affect many aspects of interpersonal and intergroup functioning so that direct communications between parties stops, the Other is viewed as non-human, relations are seen as hopeless, the conflict is framed in terms of survival needs, and the outcomes are seen as lose-lose with a desire to inflict as much harm on the other as possible (Fisher \& Keashley, 1990). Overtime, they can lead to structural changes in groups, like runaway norms, the rise of militant leaders and subgroups, and extreme forms of community polarization (Rubin, Pruitt, \& Kim, 1994). This results in aggressive-defensive maneuvers that tend to take on a life of their own and lead to outcomes of mutual loss and harm (Deutsch, 2002). Malignant conflicts can occur in personal relationships, families, organizations, communities, or within and between 
nations, and are typically wrought with misery, high economic and social costs and a profound sense of hopelessness (Coleman, 2006).

Over the past twenty-five years, 85 countries have experienced some form of major armed conflict (Marshall and Goldstone, 2007). In four regions of the world, the number of armed conflicts increased between 2002 and 2005, and today some 56 armed conflicts are being fought, with 18 of them being long-term conflicts (lasting 10 years or more; Department of International Development Report, UK, 2006).

The costs of violent protracted conflicts are enormous, and go beyond the obvious loss of lives and destruction of property (see Coleman, 2000; Kriesberg, 2005). For example, in the Democratic Republic of Congo, most of the estimated 4 million conflictrelated deaths between 1998 and 2004 were not the direct result of violence, but of the epidemics of malnutrition and disease that the conflict brought with it. According to the UK International Development Report (2006), half of the countries where life expectancy, income, and education declined in 2006 had experienced violent conflict. From an economic perspective, the average cost of one major armed conflict is nearly equivalent to the value of annual development aid worldwide. Even when violent conflict has ended, it can easily return. On average, $40 \%$ of ethnopolitical conflicts which have ended restart within ten years (Department of International Development Report, UK, 2006).

\section{Malignant Conflict and Pervasiveness}

Traditionally, the destructiveness of long-term conflicts have been assessed either by measuring their intensity in quantitative terms, which typically includes counting the number, types, and magnitude of bombing attacks, battles, fatalities, injuries, population 
displacement, etc. (e.g. Heidelberg Institute for International Conflict Research), their temporal scope or how long they persist (e.g. UPPSALA Conflict Data Program), or by assessing the direct consequences of conflicts, which entails the examination of the physical and psychological welfare of those caught up in the dynamics of conflict, and the damage to the social, political, economical, and educational infrastructure of the society (United Nations OCHA reports).

However, in describing the basic nature of long-term intractable conflicts, Zartman (2005) concluded that "intractability is a dynamic, self-reinforcing condition; digging an ever-deepening hole for itself and feeding itself like a vortex” (p. 55). In other words, the longer violent conflicts persist, the more they spread into the fabric of societies, and therefore the longer they last. The spreading of negativity into previously unrelated aspects of one's life is vividly illustrated in the above quote by a Palestinian. Here, a walk at the shore provides a painful reminder of loss and of the divisions within the society, culminating in a renewed sense of rage and resentment.

The observation that destructive conflicts have a tendency to spread and that this increase in their range prolongs and sustains their negative effects has been made by various conflict scholars (Coleman, 2000, 2003; Rouhana \& Bar-Tal, 1998; Kriesberg, 2005; Zartman, 2005; Gray, Coleman, Putnam, 2007; Wessels, 2007). However, despite decades of research dedicated to the study of protracted conflict dynamics (see Azar, 1983, 1990; Burgess and Burgess, 1996; Coleman, 2003, 2004, 2006; Crocker, Hampson, and Aall, 2004, 2005; Deutsch, 1973; Druckman, 2001; Kelman, 1997; Kriesberg, 2005; Zartman, 1989), to date, little is known about the basic mechanisms which account for the spreading of conflict, or the conditions which make it more or less likely to occur. In 
fact, other than anecdotal accounts, there has been little or no scholarship directly conceptualizing and investigating the conditions and processes involved in conflicts becoming more pervasive. This paper will attempt to address this gap in the literature.

\section{Background on Conflict Pervasiveness}

Zartman's (2005) observation on the nature of intractability captures a core dynamic, which we suggest is the essence of how conflicts become pervasive:

They [conflicts] are not static; they grow, in both degree and nature, extending and defending themselves, so that efforts to overcome them must penetrate several layers and deal with their protective dynamics [....] intractability feeds on intractability and grows with the feeding $[\ldots]$ the importance of protraction lies not in its numerical duration but in that duration's effect. (p. 49).

Other scholars have made reference to the spreading of conflicts overtime, and have specified a few related processes and outcomes. For example, Rouhana and Bar-Tal (1998) describe several aspects of public life that can become affected by conflict when it is highly central and "total”. They write:

[When conflicts are total] they penetrate the societal fabric of both parties and force themselves on individuals and institutions. Leaders, publics, and institutions-such as educational and cultural systems- become involved in the conflicts. At some stages of the conflicts, the intellectual life and scholarly inquiry become politicized as interest in the other society originates in the motivation to "know your enemy" and inquires become guided by security needs and considerations...[centrality] is reflected in the group members' preoccupation with the conflicts. Thoughts related to the conflict are highly accessible and are 
relevant to various discussions within each society (Bar-Tal, Raviv, \& Freund, 1994). The centrality of such conflicts is further reflected in their saliency on the public agenda. The media and the political and intellectual elites are greatly preoccupied with the conflicts and their developments (p. 762).

Similarly, in Coleman's (2003) discussion of the many characteristics of intractable conflict, he noted that unlike tractable conflicts, intractable ones often have unclear boundaries, which makes it difficult to depict what they are and are not about, who exactly they concern and who they do not, and when and where it is appropriate to engage in the conflict. He Writes:

In intractable conflicts the experience of threat associated with the conflict is so basic that the effects of the conflict spread and become pervasive [...] The existential nature of these conflicts can impact everything from policy making, leadership, education, the arts, and scholarly inquiry to the most mundane decisions such as whether to shop and eat in public places (Coleman, 2003; p. 27). Overtime, Coleman suggests, these negative effects on many basic aspects of life can become normative and affect people's expectations and tolerance of the status quo of destructive conflict.

Wessells (2007) provided other examples of psychosocial changes that occur as conflicts persist. He stated:

In Angola, during its war of nearly 40 years, it was not uncommon for people to say they couldn't plan for next year because of so much uncertainty. But when one probed, it seemed the larger problems were hopelessness and the disruption of collective dialogue and planning associated with being forced into a "it's every 
person for himself" mode. Besides the shrunken planning horizon, there is a general sense of futility that seems to reflect a "what's the use?" attitude that nothing one does can make much of a difference. Also, pervasiveness is expressed in increased levels of violence in families, increased use of fighting as a means of handling conflict in the village, and at other levels as well. The problem is, there are sporadic, anecdotal accounts of these phenomena but little in the way of systematic evidence (Wessells, 2007).

Kriesberg (2005), specified the processes that enable intractable conflicts to grow and expand and referred to them as "institutionalizing destructive conflict". He argued that institutionalizing of conflict occurs via socialization and internalization processes. He noted:

Once a conflict is under way, many processes contribute to its institutionalization and self-perpetuation. As a conflict persists, many members of each side increasingly view members of the other side as enemies with many bad qualities, as cruel and unworthy. Such socialization contributes to a conflict's further intractability. In addition to internalizing attitudes and beliefs about each other, people on each side develop guiding rules about how to wage their struggle. The rules make certain means of struggle legitimate, and as the authorities and others waging the struggle seem to support the rules and even punish dissenters, the rules increasingly constrain conduct. Alternative courses of action become ever more difficult to undertake (p.74).

In order to legitimize and perpetuate destructive practices, individuals and groups often adopt myths regarding conflicts (e.g. the fairness of the ingroup, evilness of the 
outgroup). Conflict is more likely to spread and become more pervasive once these myths become infused into the "conflict-resolving" structures, thereby institutionalizing things like group dominance, bias, and further conflict (Rapoport, 1974; Smyth, 2002; Coleman, 2003). Gray, Coleman, and Putnam (2007) addressed processes of institutionalization in settings of intractable conflicts, which is defined as "a gradual accretion of habitual behaviors that eventually diffuse across actors and organizations” (p. 1420). They noted that what is ironic about the complex dynamics of intractability is the development of regularized and institutionalized patterns of destructive behaviors that become entrenched, taken-for granted and resilient over time. As a result, changes happen in the psychological states of individuals, the structure and functioning of groups, and the broader community in which the conflict is situated.

To summarize, conflict scholars have described a wide-variety of distinct but related aspects relevant to how some conflicts spread and become pervasive. The following table summarizes these processes and outcomes of conflict pervasiveness on psychological, social, and structural levels.

\section{INSERT TABLE 1}

The above summary speaks to the complexity of the phenomena of conflict pervasiveness. Although this scholarship has moved our comprehension forward, our current understanding of this process remains complicated, piecemeal and somewhat confused. In subsequent sections of this paper, we attempt to add clarity, specificity and parsimony to our understanding of conflict pervasiveness.

\section{Defining Conflict Pervasiveness}


The Oxford English Dictionary defines the word pervasive as "something that is widespread through something, and that has the quality or the power of penetrating or pervading”. This generic definition of the term is a good starting point. But what does it mean to say that a conflict has become pervasive? We suggest that there are two key aspects to the phenomenon. The first is when conflict behaviors (e.g. using violence), cognitions (e.g. ingroup versus outgroup attitudes), or emotions (e.g. hate and fear) spread and begin to negatively affect aspects of life that were previously independent and considered unrelated to the conflict. For example, when the decision to shop at a store or café is constrained or determined by ethnopolitical conflict. The second aspect is when these elements of life that have become affected by the conflict begin to change their functionality and start to feed the negativity and intractability of the conflict. For instance, we saw this when a walk at the shore resulted in triggering a deep sense of resentment and rage at the site of "occupied" Palestinian homes. Thus, pervasiveness occurs when aspects of ones life that were previously unrelated to conflict become negatively affected by the conflict and begin to trigger and feed hostilities.

\section{Why Conflicts Become Pervasive}

Why and under what conditions do conflicts become pervasive? From an individual perspective, we suggest that the experiences of stress, anxiety, and trauma are some of the key factors that facilitate the spreading of conflict psychologically. Many of the normal coping mechanisms that act to protect and insulate individuals from the psychological damage and stress of protracted trauma can paradoxically impair their capacity to process new or contradictory information (Lazarus, 1985, Coleman 2003). Thus, the incapacity to process and incorporate contradictory information into one's 
sense of the outgroups, the issues, and one's ingroup leads to a strengthening of enmity and of the polarized sense of us versus them. Such closed-loop processing can lead to the development of new cognitive-affective associations that are consistent with one's original perspectives on the conflict (citation?). Furthermore, under circumstances in which defensive coping mechanisms are effective in protecting people from psychological harm, the motivation to seek alternatives to violence and destructive behaviors is diminished (Rouhana \& Bar-Tal, 1998). This can also lead to the expanding of conflicts. To state it simply, if something is working, we keep doing it.

In general, the higher the level of one's experienced stress and threat to survival, the stronger the associations created among negative thoughts and cognitions and the more likely an individual will act on them (Jarymowicz and Bar-Tal, 2001). These mechanisms are likely to be operative in situations of intense conflict, where one's life, safety, and collective identity are threatened on daily basis (Bar-Tal, 2007). Even in cases, where an individual hasn't experienced direct threat, one can still experience high degrees of anxiety, a phenomenon that has been labeled as "secondary traumatization". According to Figley (2002) secondary traumatization can result from a close awareness of trauma experienced by others, particularly individuals with whom one identifies or maintains meaningful relations (Musallam, Ginzburg, Lev-Shalem, Solomon, 2005). This in turn can lead individuals to activate further develop negative cognitive-affective associative networks that perpetuate conflict. Jarymowicz and Bar-Tal (2001) examined the different operating mechanisms of positive and negative affects. They argued that fear is a primary negative emotion based on the past and the present affective experiences is processed both consciously and unconsciously. Contrary to that, an affect such as hope is 
a complex secondary positive emotion is based on cognitive activity of deliberate thinking accompanied by positive affective components. Therefore, it is much easier for negative affect to be activated among human beings.

From a group perspective, social influence processes are central to conflict pervasiveness. In fact, a study conducted by Hill and Rothchild (1986) which examined the conditions under which political conflicts spread among groups and potentially beyond national boundaries showed that such a spread has been best understood as a process of social learning and social action. In other words, "people adopt new attitudes, develop preferences for one another, change the frequency of certain behaviors, or take on new activities because they in effect have been trained to do so" (Vallacher, et.al., p. 384). In general, people are motivated to do things that bring about pleasant consequences and avoid unpleasant ones (Higgins, 1997; Vallacher, Nowak and Miller, 2003). Furthermore, compliance is often driven by social norms. At the individual level, norms provide a moral compass regarding how to behave in situations that might offer a number of action alternatives, where at the group level, they provide "continuity, stability, and coordination of behavior among individuals” (Vallacher, et. al, p. 393). Within conflict settings, if a norm to dehumanize an outgroup becomes strong, then it is likely that many ingroup members will behave in accordance to the norm, which will eventually facilitate the spread of conflict. In addition, Patriotism- the attachment of group members to their group and the country in which they reside (Bar-Tal, 1993, p. 48) is another key process that facilitates the spread of conflict malignancy. During times of threat, it increases the cohesiveness of individuals (Doob, 1964), and it contributes to group and national unity. Typically, both patriotism and unity require the setting aside of 
any internal conflicts, voicing of disagreements, and dissent, all in service of consolidating forces to counter the outgroup threats (Bar-Tal, 1998). Once these psychological and social processes get adopted by group members. The emergence of behaviors and routines characterized by "some degree of social consensus" regarding the values of these behaviors and their adaptation (Tolbert, Zucker, 1996, p. 182; Gray, Coleman, Putnam, 2007, p. 1420), result in institutionalization process, so all social institutions such as education, justice, and even healthcare systems can face the threat of the enemy. Following sections will detail the mechanisms that govern the spread process.

\section{An Exploratory Study on Pervasiveness in the Israeli-Palestinian Context}

The Israeli-Palestinian conflict represents the epitome of a malignant conflict, and therefore we see it is an ideal case to try to validate the existence of the phenomenon of conflict pervasiveness, and to attempt to identify its basic dimensions. For the

purposes of this study, conflict pervasiveness was defined for participants as the range of issues and social processes that are organized into the structure of the conflict versus those that are "conflict free". Our task was to try to distinguish those elements of dayto-day life in this setting that, at any given time, serve to drive the conflict (move people toward anger or aggression against outgroups) versus those that are perceived to be irrelevant to the conflict, or those elements that serve to constrain the conflict (move people toward a sense of empathy or compassion with outgroups).

Participants: Fourteen university students aged 21-32 years old agreed to participate in a series of interviews and focus groups. Of the fourteen, six were selfidentified Israelis and eight were self-identified Palestinians. Six were males and eight 
were females. Ten of the participants were residing in Israel, and four of them were living in New York when the interviews/focus groups were conducted.

Procedure: participants were recruited via advertisements that were posted on university campuses (in Israel and the United States). Four individual interviews were arranged (two with Israelis and two with Palestinians), and three focus groups were conducted. At the beginning of the study, we asked our participants to think about their typical day and after that list those activities that were viewed as being "related to the conflict" and those that were "conflict free".

We presented them with the following question "We think that as the situation deteriorates and persists, more and more aspects of peoples' daily life become affected by it and serve to trigger or perpetuate a sense of anger/resentment/contempt. Does that make sense? Please share examples with us”.

Results: During the first phase, when we asked participants to list those activities that are "related to the conflict" and those that are "conflict free”, overall, both Israelis and Palestinians found the task to be challenging. For example, one of the Israeli participants argued the following "When you grow up in a conflict, conflict is your reality, that is life, that is the way things are. It is so difficult for me to distinguish what is related and what is not related to the conflict". This experience was shared by others, and illustrates how "conflict saturated" the Israeli and Palestinian societies are. When participants were presented with the statement: "As the situation deteriorates and persists, more and more aspects of peoples' daily life become affected by it and serve to trigger or perpetuate a sense of anger/resentment/contempt”, they all agreed strongly with it. 
In general, there were some similarities and some differences in the answers given by Israelis and Palestinians. As for similarities, all participants expressed strong emotional experiences that included a sense of helplessness, insecurity, hopelessness, frustration, anxiety, fear, and anger. These feelings were central to their experiences of conflict pervasiveness. For example, a sense of insecurity by Israeli participants reinforced the need to use violence against the Palestinians, where anger and hopelessness expressed by Palestinian participants supported the use of violent tactics against Israelis.

In addition, some participants noted that as things escalated in their communities, the degree to which they participated in certain activities changed. For example, the number of times they check the news updates and the number of phone calls they made during particular days changed as a function of conflict escalation. As one of the participants put it "It is not only about what you do, but how often you do certain things and for how long they last”. Finally, both Israeli and Palestinian interviewees argued that the degree to which they got affected by the conflict depended to a large extent on their relative physical proximity to high/low conflict intensity locales. Those residing closer to places where violence occurred experienced a much broader sense of contagion than those who lived in relatively more peaceful locations.

As for differences among Israelis and Palestinians, Israelis viewed conflict pervasiveness as something that was more related to specific periods and incidents (e.g. when bombing attacks occurred), while Palestinians attributed conflict pervasiveness more consistently to their every-day experiences. In addition, for Israelis, "conflict pervasiveness” was associated mostly with psychological dimensions (e.g. decision 
making processes), where for Palestinians, conflict pervasiveness was associated with tangible things (e.g. the ability to go to a hospital).

In summary, our exploratory study revealed several important points. First, it provided us with some preliminary empirical support of the phenomenon of pervasiveness. Second, our findings highlighted the difficulty experienced by participants in distinguishing between what is related and what is unrelated to conflict in situations of protracted ethnopolitical conflict; the experienced fussiness of conflict boundaries. Third, it pointed out the different qualitative experiences expressed by various populations. Finally, our exploratory study identified various aspects of conflict pervasiveness which included behavioral, cognitive, and affective components.

It is important to note that the exploratory nature of this study comes with its limitations. Despite evidence of the phenomenon, the data was not collected in a controlled manner. Thus, we were not able to quantify the degree to which the conflict had spread in this setting because we lacked appropriate measurement and comparison groups. This highlights the need to develop new research tools that can overcome these limitations.

\section{The Relevance of Dynamical Systems Theory for}

\section{Understanding Conflict Pervasiveness}

Conflict pervasiveness is dynamical by its nature. At its essence, it is an evolving, , changing set of cognitive, emotional, behavioral, and/or structural elements that grow in number, connectedness and size overtime. In this way, it is similar to the spread of a fire through a forest or a communicable disease through a community. Therefore, we need to 
adopt a conceptual framework for studying it that can help us to better understand these evolving, proliferating dynamics.

An examination of various models of biological and social elements that have the capacity to spread (e.g. contagion and diffusion models of attitudes, epidemiology of diseases such as the spread of HIV) reveals the utility of using frameworks informed by complexity science, including complex systems theory, network models, and dynamical systems theory. Such frameworks have been fruitfully applied to processes of stereotyping (Operario and Fisk, 2001, McClelland, Rumelhart, \& Hinton, 1986) aggression (Read, Vanman, \& Miller, 1997; Read \& Miller, 2002; Shoda, Tiernan, \& Michel, 2002) the self (Vallacher \& Nowak, 1994), personality (Read \& Miller, 2002; Shoda, Tiernan, \& Michel, 2002), and to the outbreak of epidemics (Morris, 2004).

Dynamical systems theory concerns the study of complex systems that evolve overtime. A dynamical system is defined as a set of elements that change overtime as each element adjusts to the myriad influences from the other elements which make up the system. These elements can be thoughts, feelings, and actions at an individual level; people, groups and norms at a social level, or various institutions such as the media, families, religious organizations, schools, etc. at a structural level. Each element can be stimulated and perpetuated along its current path through positive feedback loops between elements, where one element stimulates another along its current trajectory and this element, in turn, stimulates the first - thus making a loop. We see this when a negative act by an outgroup member links to negative memories and feelings from previous encounters and act to increase a general sense of animosity toward the outgroup and increase the likelihood that they will perceive future acts as negative. Elements can 
also be inhibited via negative feedback loops where one element constrains another (Coleman, Bui-Wrzosinska, Vallacher, Nowak, 2006). We see this when a sense of guilt or compassion arises within us and buffers our hostile intentions or actions.

Feedback loops can exist within each level and between levels. For instance, the perception of outgroup members as a "savage" by an ingroup member can be reinforced psychologically by other thoughts and feelings that are consistent with this assessment, as well as socially by the number of other ingroup members that hold similar beliefs,. At a group level, individuals can mutually influence and inform each other in a process that creates increasing homogeneity within subgroups resulting in increased conformity, or they can contradict and inhibit each other through processes such as dissent which eventually results in increased heterogeneity of opinion within groups.

We suggest that the spread of malignancy overtime in a conflict can be usefully characterized as an increase in positive feedback loops and a decrese in negative feedback loops between various elements both within and between the psychological, social, and structural levels. Psychologically, loops become established between various negative conflict-related attitudes or thoughts which link with other negative emotions within an individual and begin to affect cognitions that were previously unrelated to the conflict. Under some conditions, these elements may be transformed, such as when neutral or positive thoughts about another person become negative. Then, the activation of this thought by external stimuli or events, would lead to the activation of other linked cognitions, thereby psychologically drawing the individual into the negativity of the conflict. 
To demonstrate how conflict pervasiveness can operate psychologically, let's return to the quote from the beginning of the article:

"The other day I was taking a walk across the shore of Jaffa [a Palestinian town prior to 1948] and I was looking at the houses that now have been converted into these galleries [...] They are very nice houses with traditional Arabic Architecture, but I got so upset just looking at them. For someone who did not grow up in the conflict, they are just houses. For me, it is not just a house, it is a house that used to belong to my relatives who, by the way, today live in a refugee camp in the Gaza Strip. I look at the house and it brings up all the history, the injustice, and the emotions. By that time, I can't even stand seeing the face of any Israeli passing by me. It doesn't matter who".

In this case, the triggering event is the sight of the homes that activated other negative thoughts and emotions (memories from the past, a strong sense of injustice and feelings of anger and resentment), which are all linked together through the structure of strong linkages supported by positive feedback loops, leading to intense emotional and potentially behavioral reactions.

Such cognitive-emotional clusters, have the capacity to spread beyond the individual psychological level and begin to operate (and create loops) through behaviors on the interpersonal and group levels, and ultimately through changes on the structural level. In other words, for any individual, the likelihood that thought A leads to thought B and emotion C is usually guided by linkages and loops among cognitions and feelings available to that individual (Shoda, Tiernan and Michel, 2002), which can link to their behavioral responses to members of group D and manifest itself within institution E.What is important to emphasize is that the spread of conflict is not necessarily bottom up (individual to institution) or top down (institution to individual), but rather they can spread in either or both direction and be mutually reinforcing as long as the system lacks negative feedback loops that moderate or inhibit the spread. 
Miller (2003) proposed that negative settings and interactions are likely to function as triggering actions which prime negative thoughts and reactions and thereby increase displaced aggression. When connections (supported by an increase in positive feedback loops and a decrease in negative feedback loops) are established between negative settings and triggering events, the triggering events are no longer necessary for displaced aggression to take place. In other words, the feelings of anger and resentment triggered by the sight of the houses may persist and even be experienced in the future without the triggering event.

Furthermore, there is evidence supporting the spread and displacement of aggression from one target group into other groups. Wessells (2007) noted that in Angola, a place torn by civil wars, aggression became more and more acceptable as a means to solving community problems, and overtime spread to other domains of life including friendships, martial relationships, work, and so forth. Wessells's (2007) observation is in accordance with what many sociologists and anthropologists have previously described. For example, Martin-Baro who has said that during war, the slaughter of individuals, the disappearance of loved ones, and the constant threat to one's life, all come to be accepted as normal despite their clear abnormality (See Martin-Baro, as citied in Aaron \& Corne, 1994, Chapt 6 and 7, pp. 108-135; Comas-Diaz, Lykes, Alarcon, 1998). Other Scholars such as Mann (1985) have observed similar phenomena labeled "normalization" and "militarization", which are processes through which war and preparations for war are increasingly regarded as normal, even as desirable social activities. This normalization and spread of violence has been demonstrated statistically in many conflict areas. Reports such as the United Nations Population Fund (UNFPA) 
have been consistently reporting increased domestic violence against women (UNFPA Report, 2006), an increase in organized and gang crimes such as kidnapping children (UN Human Right Report, Iraq 2006), and an increase in sexual abuse and trafficking (UN Human Right Report, Iraq 2006; UNFPA Report, 2006) in conflict zones.

It is important to note that we use the spread of aggression here as an illustration, but the process is similar to other psychological and social processes that have the capacity to spread. For example, conflicts are usually characterized by attitudes of intolerance toward outgroups (Sullivan, Shamir, Walsh \& Roberts, 1985; Shamir, SagivSchifter, 2006). Again, with the spread of conflict, we witness a "spillover effect" of intolerance to other subgroups which are not part of the ingroup (with regard to a particular conflict). For instance, we often witness increased intolerance towards other ethnic and religious minority groups (Shamir, Sagiv-Schifter, 2006), increased political intolerance in comparison to other peaceful societies (Sullivan, 1993), and increased intolerance towards gay and lesbian communities (UN Human Right Report, Iraq 2006) under situations of protracted conflict.

Finally, the feedback loops of the dynamical systems perspective have additional utility for understanding the spread of malignancy at the structural level. Rouhana and Bar-Tal (1998) have noted that in areas of intractable conflict, cultural and entertainment institutions such as theater, film, and museums, and educational institutions, all align together to serve the conflict agenda. For example, educational institutions (both formal and informal) typically encompass the teaching and learning of specific skills in various disciplines, and the imparting of knowledge. However as conflicts become more pervasive, these educational institutions join the conflict by perpetuating societal beliefs 
and conflict ethos that instigate conflict (Bar-Tal, 1999) instead of keeping to their original mission of educating the general population (De-charms \& Moeller; Luke, 1988; Bar-Tal, 1998). This is achieved through the publication and use of biased history and social studies textbooks. In informal settings, we can observe a similar transformation in national history museums and art exhibits which propagate the "official" conflict narratives and often constitute collective memory (Savelsberg and King, 2005).

\section{Measuring Conflict Pervasiveness}

Measuring conflict pervasiveness is a difficult task. It is especially challenging given the construct's multi-level, multi-dimensional, and dynamic nature. In this section we will offer a starting point on how to approach measurement. In order to capture the spread of negativity in conflicts, we need to be able to measure two key components of the phenomenon: the extent to which conflict negativity starts affecting aspects of life that were previously unrelated to the conflict, and the extent to which these aspects start feeding the negativity of the conflict (thus constituting a feedback loop). On the psychological and social level, explicit and implicit measures can be used to measure the two aspects of the phenomenon. We could measure them in terms of the strength of the associations developing between the various elements (these could be associations in thoughts and emotions, associations within and between groups, or associations between institutions - such as the strength of the link between religious and political institutions in a religious conflict), as well as the type of association (inhibitive versus simulative). The directionality of links will also need to be assessed.

The mouse paradigm, a measurement technique developed by Vallacher and Nowak (1994), can serve as a tool to assess the degree to which aspects of life that get 
linked to a conflict (first component). This approach employs a computer and a computer mouse and asks people to assess their experience of their own thoughts and actions overtime by manipulating a cursor on a computer screen. In the context of assessing conflict pervasiveness, the participant would be asked to recount the decisions and activities in a typical day, from the moment of waking up until they go to sleep. Participants would be encouraged to describe the day chronologically and in detail, and it would be tape recorded. After that, the participants would listen to their tape recorded material, and be asked to adjust the curser in relation to a circle (in this case it represents conflict-related experiences) by moving the mouse to express their moment to moment feelings of the target (decision, activity, ect.) over a period of several minutes.

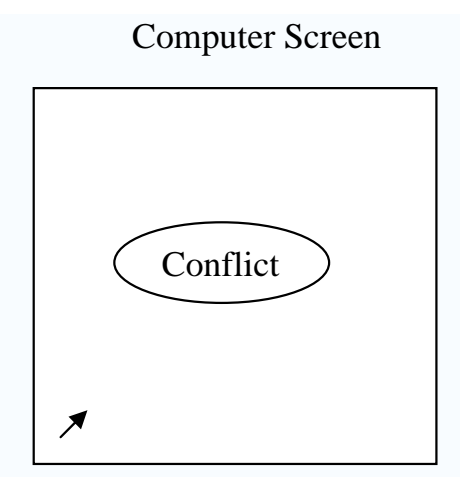

1. Unrelated to the conflict activity

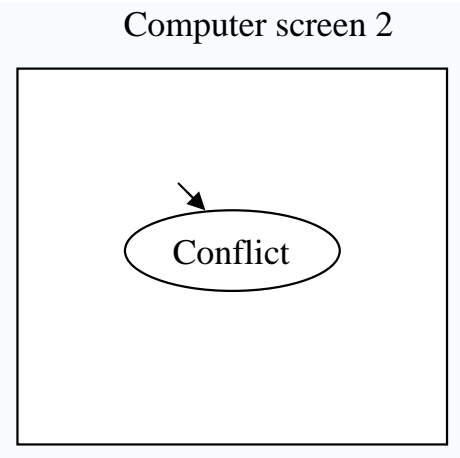

2. Activity closely related to conflict

For example, when a participant experiences a specific activity to be associated with a conflict (e.g. whether to visit a particular shop), then she or he should move the curser toward the circle by moving the mouse. This placement of the cursor in relation to the target circle represents their association of the thought or action as conflict-related or unrelated at each point in time. The closer the cursor is placed to the circle the more 
relevant that thought or action to the conflict. Figure 2 presents an example of output data from such an analysis. Here, we can see a vacillation of associations from those related to those unrelated to the conflict overtime. Thus, this situation would be described as one of moderate conflict saturation.

Another way to measure the first component of conflict pervasiveness is to present participants with ambiguous scenarios from political, economic, and social realms of life, and to measure the extent to which they are interpreted and understood through the conflict. In other words, examine the level of associations they make to the conflict in their explanation of the events. These approaches follow the same logic as one employed to measure "egocentrism” (Looft, 1992)- the incapacity to integrate various perspectives, and instead view the world only from your perspective (Reykowski, 1996; Golec, 2002). In a sense, we are trying to measure "conflict-centrism”, the degree to which everything is viewed, experienced, and touched by the conflict.

In order to assess the extent to which these associations feed the conflict (second component of pervasiveness), we could ask participants to once again code their description of their daily experiences, this time manipulating the mouse to indicate moments when their activities generated a sense of anger at members of the outgroup in the conflict, and moments when they did not. This would allow us to track, overtime, the degree to which events in daily life feed the conflict.

Another approach to assessing the extent to which daily activities feed conflict would be to ask a series of questions examining participants' decision-making processes related to daily life activities (e.g. shopping, going to a restaurant, reading books, sports, etc.). Using this approach we can assess the degree to which daily life activities are 
affected or touched by the conflict and the extent to which they fuel the conflict. For example, when an individual indicates that the choice of reading a book is touched by the conflict, we could closely examine several aspects related to the activity, such as the content of the book (e.g. accurate information versus propaganda material), the way it makes her/him feel (e.g. further anger and resentment or sympathy), and the actions taken as a result of reading the book (e.g. joining peace movement or militant group). Another approach is based on the Guttman scale. For example, the Bogardus Social Distance Scale measures people's willingness to participate in social contacts of varying degrees of closeness with members of diverse social groups, such as other racial and ethnic groups, LGBT community, and sex offenders. Items could include: “are you willing to permit X member to live in your community", "are you willing to permit X member to live in your neighborhood”, “are you willing to permit X member to live in your neighborhood”, “are you willing to permit X member to live next to your door”, and “are you willing to let your child marry X member”. Such a measure would allow one to assess the degree to which the enmity of the conflict has affected peoples’ willingness to interact with members of the outgroup.

Finally, in order to measure conflict pervasiveness on the structural level, we need to examine the extent to which the institutions have become affected by a conflict, and the degree to which they may be fueling it. We suggest that while the first aspect is related to the degree of institutional functionality-dysfunctionality, the second aspect is related to the degree to which the functions of the institution have been transformed to serve the conflict. The first involves a disruption of functionality, and the second entails the alteration of functionality. For instance, assessing the first aspect of conflict 
pervasiveness in school settings would require the examination of: the number of days that a school is closed because of bombings, changes in budget allocations due to the conflict, and how easy or difficult it is to get to school because of the conflict (In the context of the Israeli-Palestinian conflict see The Israeli Information Center for Human Rights in the Occupied Territories; United Nations Relief and Works Agency, Israeli Defense Forces ). However, in order to assess the second aspect of conflict pervasiveness, we need to carefully examine changes occurring within different institutions over time, which often requires a qualitative examination of the particular social institution. For example, in educational settings, this can be assessed through content analysis of relevant textbooks such as history, literature, and politics (for more details on how content analysis methods can be conducted with textbooks, please see Firer, 1985).

The methodological challenges of systematically mapping psychological, social, and structural trends related to the spread of malignancy in conflict are difficult but not impossible. The various methods sketched here are simply a first pass at such an approach. We encourage scholars and students to further develop these methods in order to expand this much needed repertoire for assessment and prediction.

\section{Conclusion}

Over the years, a substantial amount of work has been dedicated to the development of measures for the assessment of conflict intensity, duration, and the many consequences of conflict intractability. In this paper, we have described another equally important dimension of long-term conflicts: their degree of pervasiveness. Through the lens of dynamical systems theory, we have attempted to describe basic mechanisms which determine how conflict cognitions, emotions, and behaviors spread 
psychologically, socially, and structurally. We propose that conflict pervasiveness is a dynamical phenomenon that can be understood through ongoing changes in the connectivity of elements reinforced by positive feedback loops, which start operating on the individual level. Over time, this connectivity can spread to social and structural levels, which may reinforce each other through the presence of positive feedback loops and the absence of negative feedback loops within and between levels (Coleman, Nowak, Vallacher, Bui- Wrzosinska, 2006). Despite our nascent abilities to describe this phenomenon, empirical evidence is still scarce. Currently, we lack adequate tools to diagnose and measure conflict pervasiveness. Developing such measures can have serious implications for how we assess long-term damage in conflit, our ability to diagnose fragile and ripe peace processes (Zartman, 1986, 2000, 2003; Coleman, 2000), how we assess the effectiveness of various intervention initiatives, and how we strengthen them before applying them within conflicted societies (Coleman 2006).

\section{References}

Azar, E. E. (1983). The theory of protracted social conflict and the challenge of transforming conflict situations. Monograph Series in World Affairs, 20, 81-99.

Azar, E. E. (1990). The management of protracted social conflict: Theory and cases. Hampshire, England: Dartmouth.

Bar-Tal, D. (1998). Societal beliefs in times of intractable conflict: the Israeli case. 
International Journal of Conflict Management, 9, 22-50.

Bar-Tal, D. (2007). Social-Psychological Foundations of Intractable Conflict. American Behavioral Scientist, 50 (11), 1430-1453.

Burgess, H., \& Burgess, G. (1996). Constructive confrontation: A transformative approach to intractable conflicts. Mediation Quarterly, 13(4), 305-322.

Coleman, P. T. (2000). Fostering ripeness in seemingly intractable conflict: An experimental study. International Journal of Conflict Management, 11(4), 300-

317.

Coleman, P. T. (2003). Characteristics of protracted, intractable conflict: Towards the development of a meta-framework - I. First paper in a three-paper series. $\underline{\text { Peace }}$ and Conflict: Journal of Peace Psychology, 9(1), 1-37, Lawrence Erlbaum Associates.

Coleman, P. T. (2004) Paradigmatic framing of protracted, intractable conflict: Towards the development of a meta-framework - II. Peace and Conflict: Journal of Peace Psychology, 10(3), 197-235

Coleman, P. T., Bui-Wrzosinska, L., Vallacher, R., \& Nowak, A. (2006). Protracted Conflicts as Dynamical Systems: Guidelines and Methods for Intervention. In A. 
Schneider \& C. Honeyman (Eds.), The Negotiator’s Fieldbook. Chicago:

American Bar Association Book.

Crocker, C. A., Hampson, H. O., Aall, P. (2005). Grasping the Nettle: Analyzing cases of intractable conflict. United States Institute Of Peace Press. Washington, D.C.

Deutsch, M. (1973). The resolution of conflict: Constructive and destructive processes. New Haven: Yale University Press.

Department of International Report, UK, 2006.

Druckman, D. (2001). Nationalism and war: A social-psychological perspective. In D. J. Christie, R. V.Wagner,\&D. D. Winter (Eds.), Peace, conflict and violence: Peace psychology for the 21st century (pp. 49-65). Upper Saddle River, NJ: Prentice Hall.

Figley, C. R. (2002). Treating Compassion Fatigue. Pheladelphia: Brunner.

Galtung, J. (1969). Violence, peace and peace research. Journal of Peace Research, 3, 176-191.

Gray, B., Coleman, P. T. , Putnam, L. L. (2007). Introduction: Intractable Conflict: New Perspective on the causes and conditions for change. American Behavioral 
Scientist, 50 (11), 1415-1429.

Golec, A. (2002). Cognitive skills as predictor of attitude toward political conflict: a study of Polish politicians. Political Psychology, 23 (4), 731-757.

Kelman, H. C. (1999). The interdependence of Israeli and Palestinian national identities: The role of the other in existential conflicts. Journal of Social Issues, 55(3), 581600.

Kriesberg, L. (1998). Intractable conflict. In E. Weiner (Ed.), The handbook of interethnic coexistence (pp. 332-342). New York: Continuum.

Kriesberg, L. (2005). Nature, dynamics, and phases of intractability. In C. A. Crocker, F. Osler Hampson, and P. Aall, Grasping the Nettle: Analyzing cases of intractable conflict. United States Institute of Peace Press: Washington, D. C.

Lazarus, R. S. (1985). The costs and benefits of denial. In R. S. Lazarus (Ed.), $\underline{\text { Stress and }}$ coping (pp.155-173). New York: Columbia University Press.

McClelland, J. L., Rumelhart, D. E., Hinton, G. E. (1986). The appeal of parallel distributed processes. MIT Press Computational Models Of Cognition And Perception Series, Volume 1, p. 3-44. 
Monty G. Marshall and Jack Goldstone. 2007. “Global Report on Conflict, Governance, and State Fragility: Gauging System Performance and Fragility in the Globalization Era.” Foreign Policy Bulletin 17 (1), 3-21.

Morris, M. (2004). Network epidemiology: A handbook for survey design and data collection. Oxford University Press: UK.

Musallam, N. Ginzburg, K., Lev-Shalem, L., Solomon, A. (2005). The psychological Effects of Intifada Al-Aqsa: Acute Stress Disorder and Distress among Palestinian Israeli Students. The Israel Journal of Psychiatry and Related Sciences, 42 (2), 96105.

Operario, D., Fisk, S. T. (2001). Ethnic identity moderates perceptions of prejudice: Judgment of personal versus group discrimination and subtle versus blatant bias. Personality and Social Psychology Bulletin, 72 (5), 550-561.

Rapaport, A. (1974). Conflict in man-made environment. Harmondsworth, England: Penguin.

Reykowski, J. (1996). On ideological thinking. Studia Psychologiczne, 2, 9-24.

Rouhana, N.,\&Bar-Tal, D. (1998). Psychological dynamics of intractable conflicts: The Israeli-Palestinian case. American Psychologist, 53, 761-770. 
Read, S. J., Miller, L. (2002). Virtual Personalities: A Neural Network Model of Personality. Personality and Social Psychology Review/Erlbaum. Vol. 6, pp. 357369.

Read, S. J., Vanman, E. J., Miller, L. (1997). Connectionism, Parallel Constraint Satisfaction Processes and Gestalt Principles: (Re) Introducing Cognitive Dynamics to Social Psychology. Personality and Social Psychology Review/Erlbaum. Vol. 1, pp. 26-53.

Savelsberg, J. J., King, R. D. (2005). Institutionalizing collective memories of hate: law and law enforcement in Germany and the United States. American Journal of Sociology, 111 (2), 579-616.

Shamir, M., Sagiv-Schifter, T. (2006). Conflict, identity, and tolerance: Israel im the AlAqsa Intifada. Political Psychology, 27 (4), 569-595.

Smyth, L. J. (2002). Identity-based conflicts: A systemic approach. Negotiation Journal, 18(2),147-162.

Shoda, Y., LeeTiernan, S., \& Mischel, W. (2002). Personality as a dynamical system: Emergence of stability and distinctiveness from intra- and interpersonal interactions. Personality and Social Psychology Review, 6, 316-325. 
Sullivan, J. L., Shamir, M., Walsh, P., Roberts, N. S. (1985). Political tolerance in context: support for unpopular minorities in Israel, New Zeland, and the United States. Boulder: Westview.

Vallacher, R. R., Nowak, A. (1994). Dynamical systems in social psychology. San Diego: Academic Press.

Vallacher, R. R. \& Nowak, A. (2007). Dynamical social psychology: Toward coherence in human experience and scientific theory. In A. W. Kruglanski \& E. T. Higgins (Eds.), Social psychology: Handbook of basic principles. New York: Guilford Publications.

Vallacher, R., A. Nowak, et al. (2007). Attracted to conflict: A dynamical perspective on malignant social relations. Understanding social change: Political psychology in Poland. A. G. K. S. (Eds). Haauppague NY, Nova Science Publishers Ltd.

Wessels (2007). Personal communications.

Zartman, W. (2005). Analyzing intractability. In C. A. Crocker, F. Osler Hampson, and P. Aall, Grasping the Nettle: Analyzing cases of intractable conflict. United States Institute of Peace Press: Washington, D. C. 


\begin{tabular}{|c|c|c|}
\hline & Processes & Outcomes \\
\hline Psychological & $\begin{array}{l}\text { - A basic sense of existential threat } \\
\text { becomes psychologically } \\
\text { overwhelming, linking previously } \\
\text { unrelated cognitions to the perceived } \\
\text { source of the threst (Coleman, 2003) } \\
\text { - Temporal horizon for planning is } \\
\text { diminished which impairs constructive } \\
\text { responses (Wessels) } \\
\text { - Internalization of negative outgroup } \\
\text { attitudes and beliefs strengthen } \\
\text { animosity (Kriesberg, 2005) } \\
\text { - A profound sense of hopelessness and } \\
\text { futility limits constructive intervention } \\
\text { (Coleman, Wessells) } \\
\text { - Highly accessible conflict cognitions } \\
\text { reinforce negative beliefs and attitudes } \\
\text { (Rouhana \& Bar Tal ,1998) } \\
\text { Daily mundane decision processes are } \\
\text { adversely affected which trigger } \\
\text { resentment (Coleman, 2003). } \\
\text { - Motivation to know (vilify) your } \\
\text { enemy increases (Rouhana \& Bar } \\
\text { Tal,1998) }\end{array}$ & $\begin{array}{l}\text { - )Security needs become salient and take } \\
\text { priority over other needs such as justice } \\
\text { and fairness (Rouhana \& Bar Tal,1998) } \\
\text { - Hate and violence becomes normalized } \\
\text { and accepted and elicit less dissent } \\
\text { (Coleman, 2003) } \\
\text { - Development of automatic, taken-for- } \\
\text { granted destructive behaviors leads to } \\
\text { unconscious perpetuation of the conflict } \\
\text { Gray, Coleman, Putnam, 2007) }\end{array}$ \\
\hline Social & 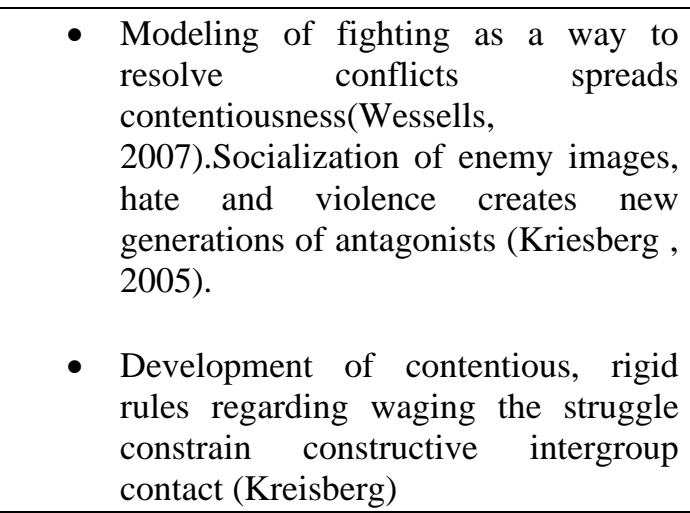 & $\begin{array}{l}\text { - Increased level of violence in families and } \\
\text { communities intensifies trauma and } \\
\text { destructive modeling (Wessells, 2007). } \\
\text { - Disruption of community dialogue and } \\
\text { planning processes impairs constructive } \\
\text { response (Wessels) } \\
\text { - Unclear boundaries of conflict issues } \\
\text { make it difficult to constructively address } \\
\text { aspects of the problem (Coleman, 2003) }\end{array}$ \\
\hline
\end{tabular}




\begin{tabular}{|c|c|c|}
\hline & $\begin{array}{l}\text { - Sanctioning of ingroup members who } \\
\text { neglect to follow ingroup rules further } \\
\text { reinforce negativity (Kriesberg) }\end{array}$ & \\
\hline Structural & $\begin{array}{l}\text { - Leaders, the media, and educational } \\
\text { and cultural institutions direct } \\
\text { attention to the conflict (Rouhana \& } \\
\text { Bar Tal,1998) } \\
\text { mobilization and patriotism ( Rouhana } \\
\text { \& Bar Tal, 1998). ?? } \\
\text { - Conflict legitimizing narratives and } \\
\text { myths support the status quo of } \\
\text { conflict and reduce opportunities for } \\
\text { constructive engagement (Kelman, } \\
\text { Coleman) } \\
\text { - Conflict institutionalization: a gradual } \\
\text { accretion of habitual behaviors across } \\
\text { actors and organizations overtime } \\
\text { solidifies polarization and enmity } \\
\text { (Gray, Coleman, and Putnam, 2007) } \\
\text { Biasing of the "conflict resolving” } \\
\text { structures, further institutionalize } \\
\text { group dominance, bias, and conflict } \\
\text { (Rapoport, 1974; Smyth, 2002; } \\
\text { Coleman, 2003). }\end{array}$ & $\begin{array}{l}\text { - Leaders, the media, and educational and } \\
\text { cultural institutions and the } \\
\text { massesrenmain preoccupied with the } \\
\text { conflict (Rouhana \& Bar Tal,1998) } \\
\text { Establishment of opportunity structures that grant } \\
\text { one party exclusive access to positions of } \\
\text { leadership, jobs, housing, education, healthcare } \\
\text { and so forth perpetuate a strong sense of injustice } \\
\text { (Galtung, 1969; Coleman, 2003). } \\
\text { - Institutionalized patterns of destructive } \\
\text { behaviors within institutions become } \\
\text { taken-for-granted (Kriesberg, 2005; Gray, } \\
\text { Coleman, Putnam, 2007)Intellectual and } \\
\text { scholarly inquiry becomes politicized and } \\
\text { oriented towards conflict, thus reducing } \\
\text { dissent and opposition (Rouhana \& Bar } \\
\text { Tal,1998; Coleman, 2003) }\end{array}$ \\
\hline
\end{tabular}

Table 1: Psychological, Social, and Structural Aspects of Conflict Pervasiveness 


\section{Mouselab Example}

Participant 68

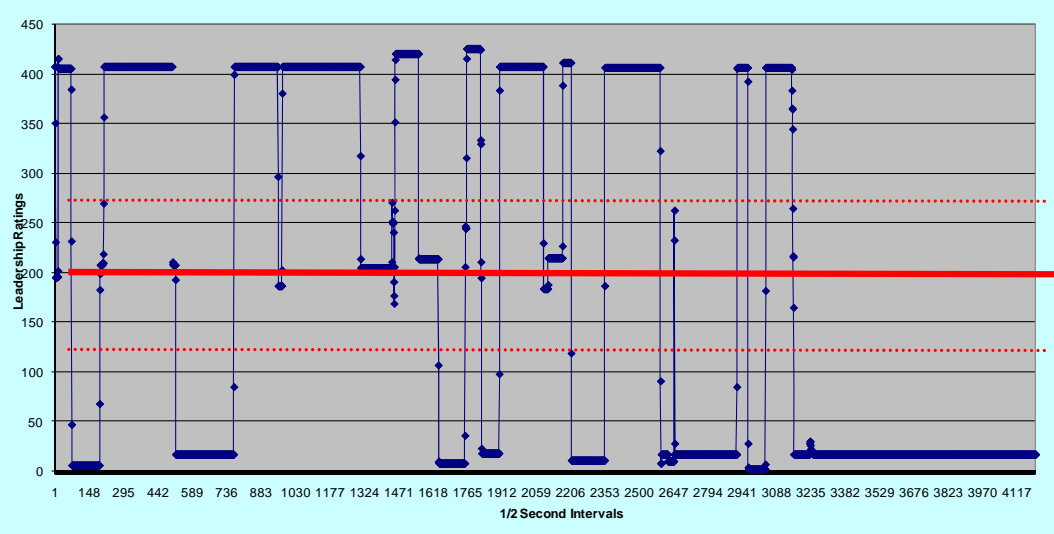

Figure 1: An illustration of data from the mouse paradigm. 